\title{
Seasonal Variation Effect on Multiple Sclerosis Activity in Patients Attending Multiple Sclerosis Clinic in Baghdad Teaching Hospital.
}

\author{
$(\text { CABM-FRCP })^{2}$, Kawther M Jabur ${ }^{3}$. \\ Maral F. Thabit ${ }^{1}$, Dr.Akram M. Al Mahdawi \\ I(F.I.C.M.S.Fm)Community Health department, Institute of Medical Technology, Baghdad, Iraq. \\ ${ }^{2}$ Neurological department, Baghdad Teaching hospital, Baghdad, Iraq. \\ ${ }^{3}$ Bab Al Muthum Primary Health Care center, Baghdad, Iraq.
}

\begin{abstract}
Multiple sclerosis is an immune mediated demyelinating disease of the central nervous system characterized by bouts of neurologic symptoms (or relapses) and increasing disability. The aim of this study is to elucidate the influence of seasonal variation on the nature and number of relapses in patients already diagnosed with multiple sclerosis.

A cross- sectional retrospective study was carried out from January to May 2011 in Multiple Sclerosis clinic of neurological department in Baghdad Teaching hospital, including 100 relapsing-remitting multiple sclerosis patients ( 26 males and 74 females) with 278 relapses who were registered over 5 years interval (2005-2010), data collected by reviewing patients records and analyzed statistically.

Patients younger than 40 years significantly constitute $76 \%$ of the sample. The largest percentages (14\%) of patients were born on July. The total number of relapses was 278 distributed as 218 in females and 60 in males, the proportion of relapses in both sexes (73.7\%) were higher in patients younger than 40 years.

Regarding the pattern of multiple sclerosis relapses; the highest percentage (29.8\%) was of sensory type. The peak of multiple sclerosis relapses was evident during January and April, with higher percentage (31.2\%) in females during Spring .there was no significant differences in the proportion of relapses (29.1\%, $34.7 \%)$ during Spring in both age groups and there was no relation between the type of relapse and season of occurrence.
\end{abstract}

Conclusion: There is some seasonal effect on multiple sclerosis relapses, they were higher in Spring, and lower in Summer.

Key Wards: multiple sclerosis, relapse, season.

\section{Introduction}

Multiple sclerosis (MS): is an inflammatory disease in which the fatty myelin sheaths around the axons of the brain and spinal cord are damaged, leading to demyelization and scarring as well as a broad spectrum of signs and symptoms ${ }^{(\mathbf{1})}$.

The etiology of MS is unknown but it is believed to have an autoimmune basis in genetically susceptible individuals as a consequence of environmental insult ${ }^{(2)}$.

Disease onset usually occurs in young adults, and it is more common in women, It has a prevalence that ranges between 2 and 150 per $100,000^{(1)}$.It afflicts over 2 million people worldwide ${ }^{(3)}$, but it's rare in some ethnic groups (e.g. Japanese), does not occur in other groups (e.g. African blacks, Eskimos) ${ }^{(4)}$ and appears to have high risk in others (e.g. Sardinians and Palestinians) ${ }^{(5)}$

Common symptoms of MS include fatigue, walking difficulties leading to reduce mobility, bowel/bladder disturbances, optic neuritis( $\mathrm{ON})$ and other visual changes , modification in cognitive function , pain, sensory loss and depression ${ }^{(1)}$.

The incidence of MS worldwide tends to increase with increasing latitude; there is a north-to-south gradient in the northern hemisphere and a south-to-north gradient in the southern hemisphere, with MS being much less common in people living near the equator. Climate, sunlight and intake of vitamin D have been investigated as possible causes of the disease that could explain this latitude gradient ${ }^{(1)}$.

Based on its course, the disease is divided into a relapsing-remitting multiple sclerosis

(RRMS) form (85\%) of cases in which progression does not occur between attacks; a secondary progressive multiple sclerosis (SPMS) form $(80 \%)$ of RRMS cases after 25 years, it's characterized by a gradually progressive course after an initial relapsing-remitting pattern; and a primary progressive multiple sclerosis (PPMS) form (10\%) of cases in which there is gradual progression of disability from clinical onset. A progressive-relapsing form occurs rarely, with acute relapses being superimposed on a primary progressive course ${ }^{(6)}$. 
Different environmental factors, both of infectious and non infectious origin have been proposed as risk factors in the pathogenesis of MS process, and a number of studies also point to a relationship between the seasons of the year in the appearance of outbreaks ${ }^{(7)}$. MS activity can increase during Spring and Summer months, the appearance of lesions on brain scan were 2 to 3 times in months of March to August compared to other months of the year ${ }^{(8)}$.An association between the month of birth and the risk of later development of MS had been documented in studies conducted in Canada, United Kingdom, Denmark, Sweden, also populations emigrating from areas of low to areas of high risk indicate that the environment is also a key factor in MS pathogenesis ${ }^{(9)}$.

Aims of study:

1- To determine the monthly distribution of MS relapses.

2- To elucidate any seasonal variation difference regarding the nature of disease, age and gender of patients.

\section{Patients and Methods}

A cross-sectional retrospective study was carried out from 1st of January to 1st of May 2011 in the MS clinic of neurological department at Baghdad Teaching hospital, where patients with definitive clinically diagnosed MS, are registered and routinely checked. The study sample included $100 \mathrm{MS}$ patients (26 males and 74 females) selected randomly with 278 relapses, who were registered in the above clinic over 5 years interval extending from 1st of January 2005 to 1 st of January 2010, choosing 5 years of data analysis would supply sufficient event number of relapses to enable us to sniff out any seasonal variation in multiple sclerosis exacerbations.

\section{Inclusion and exclusion criteria:}

MS patients with relapsing -remitting type were involved, each relapse event was checked by at least one of the neurologists to ensure the satisfaction of inclusion criteria of relapse as the appearance of new symptoms or worsening of an old one attributable to MS lasting more than or equal 24 hours, and preceded by stability or improvement for more than or equal 30 days. Frequent attacks that were experienced by the same patient were considered separate relapses only when the interval between each exceeded one month duration. Pseudo attack that might be due to change in the core body temperature with infection lasting less than 24 hours was excluded. ${ }^{(1)}$

Data collected by reviewing the medical records of the involved patients regarding (name of patient, date of birth, gender, date of diagnosis, pattern and date of relapses).

Patients were categorized into two groups, according to the age $<40$ years or $\geq 40$ years. This age criteria was chosen since relapses are age dependent, also the multiple sclerosis relapses were categorized into one of the 12 months and 4 seasons of the year, the attacks were further subdivided into 5 groups according to the pattern of relapses (sensory, motor, optic neuritis , cerebellar, and others).

The collected data was analyzed by (SPSS 18) program. Discrete variables presented as numbers (N) and percentages (\%).Chi square test for goodness of fit used to test the significance of an observed distribution and to test the significance of association between two discrete variables .Tests are two sided and $\mathrm{P}$ value is a asymptotic , finding of $\mathrm{P}$ value $<0.05$ is considered to be significant ${ }^{(\mathbf{1 0})}$.

\section{Results}

The study included 100 clinically definite multiple sclerosis patients with relapsing- remitting course. The results show that (MS) patients younger than 40 years significantly constitute $3 / 4$ of the sample, $84.6 \%$ of male patients were $<40$ years, while $73 \%$ of female patients were <40 years, the results gave statistically significant differences ( $\mathrm{P}$ value $<0.05$ ), as shown in table (1).

Table 1: Distribution of cases according to age and gender

\begin{tabular}{|c|c|c|c|c|c|c|}
\hline \multirow[b]{3}{*}{ Age(year) } & \multicolumn{4}{|c|}{ Gender } & \multirow{2}{*}{\multicolumn{2}{|c|}{ Total }} \\
\hline & Male & & Femal & & & \\
\hline & $\mathrm{N}=26$ & $(100 \%)$ & $\mathrm{N}=74$ & $(100 \%)$ & $\mathrm{N}=100$ & $(100 \%)$ \\
\hline$<40$ & 22 & 84.6 & 54 & 73.0 & 76 & 76.0 \\
\hline$\geq 40$ & 4 & 15.4 & 20 & 27.0 & 24 & 24.0 \\
\hline$P$ value & 0.000 & & & & 0.000 & \\
\hline
\end{tabular}


The highest percentage (14\%) of MS patients were born in July while the lowest percentage (3\%)where born in October, statistically there was no significant association between month of birth and development of multiple sclerosis $(\mathrm{P}$ value $>0.05)$, as shown in table $(2)$.

Table2: Distribution of MS cases according to month of birth.

\begin{tabular}{llll}
\hline Date of birth in months & $\mathrm{N}=100$ & $100.0 \%$ & P value \\
\hline & 10 & 10.0 \\
January & 6 & 6.0 & \\
February & 11 & 11.0 \\
March & 9 & 9.0 & \\
April & 8 & 8.0 & 0.453 \\
May & 8 & 8.0 & \\
June & 14 & 14.0 \\
July & 9 & 9.0 & \\
August & 6 & 6.0 & \\
September & 3 & 3.0 & \\
October & 10 & 6.0 & \\
November & 6 &
\end{tabular}

The proportion of relapses were higher $64(29.4 \%)$ in females compared to males 9 (15\%) in age group $\geq 40$ years while the proportion of MS relapses in both sexes $(73.7 \%)$ were higher in patients < 40 years old. The results gave statistically significant difference ( $\mathrm{P}$ value $<0.05)$, as shown in table (3).

Table3: Distribution of MS relapses according to age and gender

\begin{tabular}{lllll|ll}
\hline & \multicolumn{3}{c}{ Gender } & \multicolumn{2}{l}{ Total } \\
\cline { 2 - 7 } Age(year) & Male & \multicolumn{3}{l}{ Female } & N=278 & $(100 \%)$ \\
\cline { 2 - 7 } & $\mathrm{N}=60$ & $(100 \%$ & $\mathrm{N}=218$ & $(100 \%)$ & & \\
\hline$<40$ & 51 & 85.0 & 154 & 70.6 & 205 & 73.7 \\
$\geq 40$ & 9 & 15.0 & 64 & 29.4 & 73 & 26.3 \\
\hline P value & & & & & & 0.025 \\
\hline
\end{tabular}

Distribution of relapses regarding their pattern, the results show that the highest percentage (29.8\%) of relapses were of sensory type followed by optic neuritis (26.6\%) of patients. as shown in table (4) .

Table 4: Distribution of MS relapses regarding their nature

\begin{tabular}{|l|l|l|}
\hline Type of relapse & $\mathrm{N}=278$ & $\%$ \\
\hline Sensory & 83 & 29.85 \\
\hline Motor & 67 & 24.1 \\
\hline Optic neuritis & 74 & 26.61 \\
\hline Cerebellar & 31 & 11.15 \\
\hline Others & 23 & 8.27 \\
\hline Total & 278 & $100 \%$ \\
\hline
\end{tabular}


The peak of MS relapses within 5-years interval was evident in January and April as shown in figure (1).

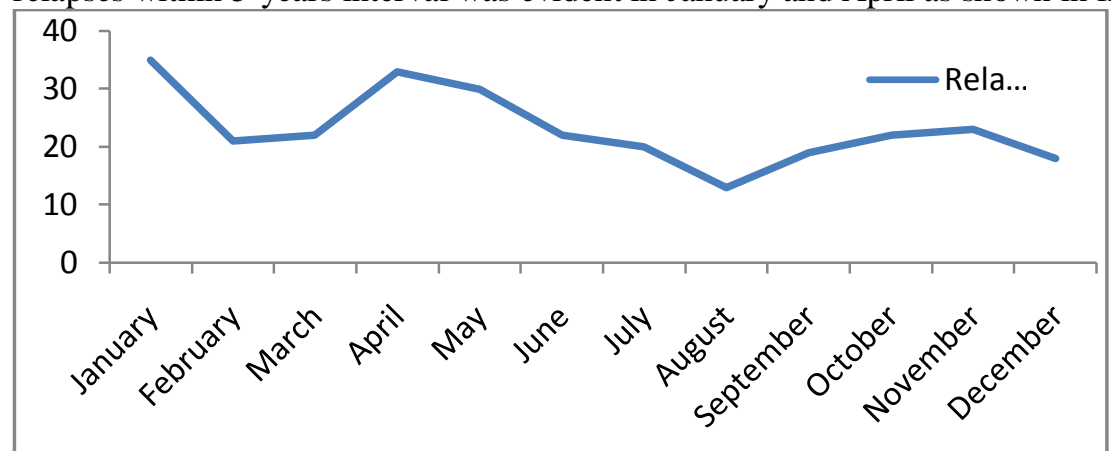

Figure1: Distribution of replaces through the months of the year.

The highest percentage of relapses $(30.6 \%)$ were during spring, also the highest percentage $(31.2 \%)$ of relapses were in females during spring. In male patients, the highest percentage $(30.0 \%)$ of relapses was during winter. The results gave statistically no significant difference (P value $>0.05)$ as shown in table (5).

Table5: Distribution of replaces through the year, according to season and sex of patients.

\begin{tabular}{lllll|ll}
\hline & \multicolumn{3}{l}{ Relapse } & \multicolumn{3}{l}{ All Sample } \\
\cline { 2 - 7 } Season & Male & \multicolumn{3}{l}{ Female } & & \multicolumn{2}{l}{ N=278 } & $100 \%$ \\
\cline { 2 - 7 } & $\mathrm{N}=60$ & $100 \%$ & $\mathrm{~N}=218$ & $100 \%$ & & \\
Winter & 18 & 30.0 & 55 & 25.2 & 74 & 26.6 \\
Spring & 16 & 26.7 & 68 & 31.2 & 85 & 30.6 \\
Summer & 15 & 25.0 & 53 & 24.3 & 55 & 19.8 \\
Autumn & 11 & 18.3 & 42 & 19.3 & 64 & 23.0 \\
\hline P value & 0.860 & & & & \multicolumn{2}{l}{0.066} \\
\hline
\end{tabular}

Proportion of relapses (29.1\%), (34.7\%) were higher during Spring in both patient's age groups. there was no statistically significant differences according to the age of MS patients and season ( $\mathrm{P}$ value > 0.05).as shown in table(6).

Table 6: Distribution of MS relapses according to age and season.

\begin{tabular}{llll}
\hline & $\begin{array}{l}\text { Age (year) } \\
<40\end{array}$ & $\geq 40$ & \\
Season & $\mathrm{N}=203(100 \%)$ & $\mathrm{N}=75(100 \%)$ & $\mathrm{P}$ \\
\hline Winter & $52(25.6)$ & $22(29.3)$ & \\
Spring & $59(29.1)$ & $26(34.7)$ & 0.573 \\
Summer & $43(21.2)$ & $12(16.0)$ & \\
Autumn & $49(24.1)$ & $15(20.0)$ & \\
\hline
\end{tabular}

The results show no statistically significant association ( $\mathrm{P}$ value $>0.05$ ) between the type of relapse and season of occurrence, as shown in table (7).

Table7: Distribution of MS relapses according to relapse type and season.

\begin{tabular}{lllllll}
\hline $\begin{array}{l}\text { Relapse } \\
\text { type }\end{array}$ & Winter & Spring & Summer & Autumn & Total & \\
& $\mathrm{N}(\%)$ & $\mathrm{N}(\%)$ & $\mathrm{N}(\%)$ & $\mathrm{N}(\%)$ & $\mathrm{N}(\%)$ & $\mathrm{P}$ \\
\hline Sensory & $20(24.1)$ & $26(31.3)$ & $21(25.3)$ & $16(19.3)$ & $\begin{array}{l}83 \\
(100.0)\end{array}$ & \\
Motor & $21(31.3)$ & $13(19.4)$ & $15(22.4)$ & $18(26.9)$ & $\begin{array}{l}67 \\
(100.0)\end{array}$ & \\
Optic Neuritis & $21(28.4)$ & $25(33.8)$ & $11(14.8)$ & $17(30.0)$ & $\begin{array}{l}74 \\
(100.0)\end{array}$ & 0.488 \\
Cerebellar & $7(22.6)$ & $14(45.2)$ & $3(9.6)$ & $7(22.6)$ & $\begin{array}{l}31 \\
(100.0)\end{array}$ & \\
Others & $5(21.7)$ & $7(30.4)$ & $5(21.7)$ & $6(26.2)$ & $\begin{array}{l}(100.0) \\
\end{array}$
\end{tabular}




\section{Discussion}

One of the characteristics of MS is the unpredictable occurrence of exacerbation and remissions .Exacerbation lead to short term morbidity, but may also influence long term disability ${ }^{(11)}$.

Findings from the study showed significant predominance of MS in patients younger than 40 years of age, as onset before 40 years typically begins as relapsing remitting MS. ${ }^{(12)}$ Similarly Sottini. et al in Germany, found that onset of the disease occurs during early adulthood (age 15-45years), making MS one of the most common causes of neurological disability in young and middle age adults ${ }^{(13)}$.

In this study MS females constitute (74\%) and males constitute (26\%) of the studied sample ,similarly other authors ${ }^{(14)(15)(16)}$ revealed female predominance, this is explained that gender influence both susceptibility to MS and the clinical course of the disease ,the basis for these differences may include genetic and immunological factors, the immunological differences between men and women may be mediated through the effects of the sex hormones ${ }^{(17)(18)}$. The percentage of relapses were significantly higher in males compared to females younger than 40 years of age ,this is contradictory the results of Salvi, et $\mathrm{al}^{(9)}$, who found that no significant periodicity in subgroups categorized by sex, and Compston et al ,a study done in Japan found that MS relapses seem to be age dependent with most occurring in persons between 20 and 40 years of age, the manifestation of MS ,therefore, appears to be dependent upon being passed through the pubertal period suggesting an endocrine influence on the timing onset of the disease ${ }^{(18)}$.

It seems that there was no significant association between the month of birth and risk of later development of MS, while a study done by including 17,874 Canadian and 11,502 British patients with MS also revealed a significant association between the month of birth and MS risk ${ }^{(19)}$.

According to Staples et al in Australia showed that people born in summer months had a higher risk of developing MS, interestingly the researchers suggest that it was the level of exposure to sunlight during the $1^{\text {st }}$ trimester as opposed to the entire pregnancy duration that was responsible for modifying the risk of developing MS in offspring $\left({ }^{20)}\right.$.

A number of studies point to a relationship between the seasons of the year and the appearance of outbreaks ${ }^{(5)}$. In this study the distribution of relapses were peaked in Spring in females and in Winter in males, similarly Fundora _ Hernandez, et al ,a study done in Cuba found that relapses occur more frequent in the first 2 quarters of the year, and their frequency is particularly higher in the $2^{\text {nd }}$ quarter of the year (April to June $)^{(21)}$, while Ogawa, et al, in Japan found that incidence of attacks was highest in July, but this monthly pattern was statistically not significant ${ }^{(22)}$. Gray et al, found that relapses were significantly more common in spring in northern hemisphere and autumn in southern hemisphere ${ }^{(23)}$.

According to Wuthrich, et al, number of outbreaks increased in Spring and Winter in Switzerland ${ }^{(24)}$, while the results of K Shapiro , there was a non significant tendency of outbreaks to increase during Summer mainly in July had been observed in UK ${ }^{(25)}$.

There are also data from USA where more outbreaks observed from July to October in Ohio and in spring in Minnesota ${ }^{(26)}$.

Regarding the pattern of MS relapses, in this study showed the predominance of sensory and ON relapses, mainly in Spring, while Ogawa et al ${ }^{(22)}$ conducted a study in Japan and found that relapses of MS patients were distinguished according to type (brain lesion and optic-spinal lesion ), there was no significant tendency for more attacks to occur in the warmest and coldest months, while a study done in Stockholm , Sweden by Jin et al, studied seasonal variation of optic neuritis, found a higher onset in Spring (70\%) and lowest in Winter(30\%) ${ }^{(27) .}$

Finally, many studies found a relation between outbreak emergences with different weather variables and seasons, when conducting analysis of the seasonal outbreaks of MS, the results have been contradictory depending on the geographical locations where these studies have been performed. These contradictory data make difficult the establishment of seasonal or month incidence of MS outbreaks that may be applicable everywhere ${ }^{(21)}$

\section{Conclusions}

- There is some seasonal periodicity of relapses; they were higher in spring and winter and lower in summer.

- Higher incidence of relapses occurred in the $1^{\text {st }}$ half of the year (January to June).

- There were 2 peaks of relapses, $1^{\text {st }}$ in January and the $2^{\text {nd }}$ in April,

- Sensory and optic neuritis relapses were the higher number of relapses in MS patients with some seasonal periodicity occurred in spring and winter.

- The total number of MS relapses were significantly higher in females compared to males and for both sexes, the number of relapses were higher in patients younger than 40 years. 


\section{Recommendations}

1-The possible relationship between season and environmental factors deserve further exploration.

2-The role played by environmental factors and endogenous human biological rhythms requires more-in-depth investigations, since it is plausible that seasonal variation of immune status and responsiveness might play a role as well.

3-Colaboration with other investigators involved in the fields of genetics, virology, immunology, and hygiene science ....etc .must be developed if researches is to continue to provide more clues.

4-Confirmation of the findings on larger multi-center population, residing in different climatic conditions to further explore the potential seasonality of multiple sclerosis relapses and associated environmental trigger

\section{References}

[1]- P O'Connor. Key issues in the diagnosis and treatment of multiple sclerosis. An overview. Neurology, 59(6 suppl3), 2002, S1-S33.

[2]- A Compton and A Coles .Multiple sclerosis (article). Lancet; (359), 2002, 1221 - 1231.

[3]- J Yan and JM Greer. NF-Kappa B, a potential therapeutic target for the treatment of multiple sclerosis .CNS Neurological Disord Drug (7), 2008, 536-557.

[4]- CM Poser, The epidemiology of multiple sclerosis, a general over view, Annals of neurology (36), 1994, 5180-5193.

[5]- G Rosati .The prevalence of multiple sclerosis in the world: an update, Neural Sci (22): 2001, 117-139.

[6]- D Miller, F Barkhof, X Montalban, etal. "Clinically isolated syndromes suggestive of multiple sclerosis, part I: natural history, pathogenesis, diagnosis, and prognosis". Lancet Neuro 14 (5), 2005, 281-8.

[7]- J -Correale, M Fiol, W Gilmore. The risk of relapses in multiple sclerosis during systemic infections . Neurology . 67(4), 2006, 6529 .

[8]- J Salzer, A Svenningsson, P Sundstrom,. Seasons of birth and multiple sclerosis in Sweden -Acta neurol Scand; 122 (9), 2010 , 7073.

[9]- F Salvi, L Bartolome., MH Smolensky, et al. A seasonal periodicity in relapses of multiple sclerosis.BMC Neurology, (10), (2010), 105 .

[10]- WD -Wayne. Biostatistics: A foundation for analysis in the health sciences 7th Edition, chapter 12, 1998, 571-600

[11]- D Buljevac, HZ Flach , WCJ Hop ,et al . Prospective study in the relationship between infections and multiple sclerosis, Brain, (125), 2002, 952-960.

[12]- ML Polliack, Y Barak, A Achiron,. Late onset multiple sclerosis, journal of the American Geriatrics Society, (49), 2001, 168-171.

[13]- A Sottini, R Capra, F Serana etal. Interferon- beta therapy monitoring in multiple sclerosis patients. Endocrine, Metabolic and Immune Disorders Drug Targets, (9), 2009, 14-28.

[14]- SM Orton, BM Herrera, IM Lee etal.Sex ratio of multiple sclerosis in Canada: Longitudinal study. Lancet Neurol, 5(11): 2006, 932936.

[15]- AD Sadovnik. European Charcot Foundation Lecture: The natural history of multiple sclerosis and gender. J Neurol Sci; 286(1-2): $2009,1-5$.

[16]- A Nicot, Gender and sex hormons in multiple sclerosis pathology and therapy. Frontiers in bioscience, (14): 2009, 4477-4515

[17]- V Tomassini, C Pozzilli . Sex hormones: a role in the control of multiple sclerosis?Expert Opin Pharmacother. , 7(7): 2006, 857-68.

[18]- A -Compston, C Confavreux, H Lassman, et al. McAlpine's multiple sclerosis. Philadelphia: Churchill Livingstone Elsevier, 2005.

[19]- CJ Willer, DA Dyment, AD Sadovaick AD,et al .Timing of birth and risk of multiple sclerosis: population based study. BMJ, 330 (7483). 2005:120-124.

[20]- J Staples ,AL Ponsonby, L Lim. Low maternal exposure in pregnancy, month of birth, and risk of multiple sclerosis in offspring: longitudinal analysis.BMJ, 2010,c1640.

[21]- H Fundoro-Hernandez, AJ. Dorta-contreras, M Socias-Lopez, etal. Seasonal distribution and evolving forms of multiple sclerosis patients diagnosed from April 2004 to November 2007. Neuropsiquiatr, 67(3- A), 2009, 661-663

[22]- G -Ogawa , H Mochizuki, M Kanazaki, et al .Seasonal variation of multiple sclerosis exacerbations in Japan. Neurol Sci; 24(6), 2004, 417-419.

[23]- OM Gray, D Jolly , C Zwanikken C, et al .Temporal variation of onset of relapses in multiple sclerosis is not seasonal: results from the MSBase registry.Neurology Asia,(13), 2008,199-200.

[24]- R Wuthrich , HP Rieder . The seasonal incidence of multiple sclerosis in Switzerland, Eup neurol, (3) 1970,257-264.

[25]- K Shapira, The seasonal incidence of onset and exacerbations in multiple sclerosis. Journal of Neurosurgery and psychiatry, (22), 1959, 285-286.

[26]- FD Lublin, SE Reingold. Defining the clinical course of multiple sclerosis: results of an international survey. National Multiple Sclerosis Society (USA) Advisory committee on clinical trails of new agents in multiple sclerosis. Neurology (46), 1996, 907-911.

[27]- YP Jin J de pedro-cuesta, M Soderstrom,etal.Incidence of optic neuritis in Stockholm ,Sweden 1990-1995, Arch Neurol.56(8): $1999,975-80$ 